\title{
Los debates entre Ciencia y Fe en el Cádiz de la Restauración borbónica: una interpretación
}

\section{JOSE MARCHENA DOMINGUEZ}

El espectacular progreso de las ciencias y las técnicas, y su capacidad para transformar los resortes civilizadores hasta entonces conocidos, produjo en la Europa de mediados del siglo XIX, una creencia desmedida en la ciencia y el progreso. El afán por explicarlo todo científicamente, favoreció un tipo de racionalismo basado en la experiencia, que a su vez hizo retroceder al sentimiento religioso tradicional, cuya base escolástica había sido hasta entonces casi incuestionable. Ello empujó a una gran parte de teóricos y pensadores, hacia un modelo social sin fe en Dios, sin metafísica y sólo asistido por un pensamiento científico o positivo. Era el turno de la doctrina positivista acuñada por Comte. Este claro proceso de secularización en Europa, puso sobre alerta a la Iglesia quien luchó, como norma de salvaguarda -caso del "Syllabus" de 1864 o el Concilio Vaticano I de 1869-1870-, contra todas las tendencias básicas del mundo moderno (1).

Entretanto en España, la mentalidad científica tuvo cada vez más protagonismo en la sociedad española con actitudes como: el positivismo, el krausismo, el krausopositivismo y el institucionismo lo que, obviamente, supuso también el choque con las instituciones eclesiásticas (2). Esto es; en el plano ideológico estas

(1) STROMBERG, Roland N., Religious liberalism in the eighteenth-century England, London, 1954, pp. 163-170 y JUARRANZ DE LA FUENTE, José $\mathrm{M}^{\mathrm{a}}$., Las transformaciones científicas, técnicas y económicas (1850-1914), Madrid, 1984, pp. 10-12.

(2) El nuevo Estado de la Restauración, se encontraba ante un dilema: por un lado, como Estado de naturaleza liberal podía echar mano del proceso secularizador y de la independencia respecto de la Iglesia. Por otro, la Iglesia, a pesar de fenómenos desventajosos a su influencia como las desamortizaciones, seguía siendo fuerte como institución y como cauce pedagógico. Por ello, la Restauración adopta una actitud transigente con la Iglesia -ésta también-, como bien lo reflejó el mantenimiento del espíritu del Concordato de 1851, aunque ello no supuso que otros sectores más progresistas, -liberales, obreros e intelectuales- arrojaran la toalla al respecto. Para más apreciaciones sobre el tema, V. TELLO, José Angel. "La Iglesia en el proceso constitucional de la Restauración". Anales de la Fundación Joaquín Costa, Madrid, 1985, n. 2, REVUELTA, M. Política religiosa de los liberales en el siglo XIX. Trienio Constitucional, Madrid, 1973, CUENCA, José Manuel. Iglesia y Burguesía en la España Liberal, Madrid, 1979, PRIETO, J. A., Púlpito e Ideología en la España del siglo XIX, Zaragoza, 1978 y NUÑEZ RUIZ, Diego. "Filosofía y política universitaria en la crisis española del fin de siglo". Anuario del Departamento de Historia de la Filosofia , Madrid, '1985-86. 
corrientes citadas engrosaron un núcleo, digámoslo así, progresista frente a otro bloque de naturaleza reaccionario y en contra de cualquier postulado proveniente de la revolución liberal. Este esquema, salvando los matices correspondientes, es el que vino a desarrollarse en el XIX español y el que vertebró la polémica entre la fe y la razón (3).

En nuestro caso y sin perder las coordenadas ideológicás descritas, intentamos hacer un incursión en el mundo de las ideas de uno de los núcleos característicos de la ideología burguesa del Cádiz de la década de los sesenta, y cuya influencia no se desvincula en el periodo de nuestro estudio. Nos referimos al núcleo krausista, grupo acaudillado por Alfonso Moreno Espinosa y Romualdo Alvarez Espino, junto a otros como Campillo, Larrahondo, etcétera y que, desde las aulas de las escuelas primarias y secundarias de Cádiz, y desde los pricipales academias y centros de reunión (4), supieron marcar el perfil de la componente ideológica en determinadas parcelas del pensamiento y de la religión, como esta cuestión que tratamos (5).

Como ya acabamos de aludir, la irrupción del idealismo alemán de Hegel y Krause en nuestras fronteras, a través de distintas iniciativas universitarias e intelectuales -en especial el famoso viaje de Julián Sanz del Río y su posterior Cáte-

(3) Esta dicotomía ha sido señalada, entre otros estudiosos, por Lain Entralgo o Abellán. A diferencia de Europa, que se intenta absorber la religiosidad cristiana, en España se adopta un esquema peculiar en el que la pugna conduce a un peligroso maniqueismo. En resumen, ambas tendencias -opinan- resultaron mediocres, con una marcada sensación de impotencia y con un afán de imitar modelos exteriores, fruto del desconocimiento de la historia y, por lo tanto, de un modelo cultural propio. En este sentido anotamos el papel ecléctico de Menéndez Pelayo, con su negación de que el catolicismo fuera un obstáculo para la ciencia y con su afán por definir un modelo histórico español integral. V., LAIN ENTRALGO, Pedro. Sobre la cultura española. Confesiones de este tiempo, Madrid, 1943, ABELLAN, José Luis. Historia crítica del pensamiento español, T. 5/ I, Madrid, 1989, pp. .335-340 y MILLAN CHIVITE, José Luis. "Evolución del concepto de Tradición como política en la España del XIX". Anales de la Universidad de Cádiz, Cádiz, 1985, n. 2.

(4) Aunque no sea el objeto primordial de nuestro estudio, no olvidamos la importante labor pedagógica efectuada por estos profesores en el Cádiz de la segunda mitad del siglo XIX, ni de sus bagaje por los principales centros -Real Academia Gaditana de Ciencias y Letras- en estrecha relación con otros núcleos krausistas como el sevillano acaudillado por Federico de Castro. En espera de los resultados de un trabajo más exhaustivo, que prepara Gloria Espigado, localizamos algunas referencias en LOPEZ ALVAREZ, Juan. "El Krausismo en Cádiz", Anales de la Universidad de Câdiz, Cádiz, 1984, MARCHENA, José. El Partido Demócrata Gaditano (1849-1868), Cádiz, 1992, pp. 205-217, "La Academia de Bellas Artes de Cádiz en la encrucijada de la Restauración: una interpretación ideológica de sus discursos". Tercer Coloquio de Historia Locales, Cádiz, 1991, y ESPIGADO, Gloria. La Primera República en Cádiz. Estructura social y comportamiento politico durante 1873, Jerez, 1992, pp. 139-159.

(5) No olvidamos tampoco la idea del interés gaditano por los progresos de la ciencia y el pensamiento, por lo nuevo en general, que fomentaron un foco de interés cultural en el Cádiz decimonónico, y que a la postre también propiciaron este avance ideológico. Botón de muestra nos la dan la famosa polémica entre Juan Nicolás Böhl de Faber y José Joaquin de Mora en 1817 en El Diario Mercantil, que de un tema tetral, derivó a un debate entre lo tradicional y lo renovador. V., RAMOS, A. Cádiz en el siglo XIX; de ciudad soberana a capital de provincia, Cádiz, 1992, pp. 132-134. 
dra de Filosofía en Madrid en 1843-, favoreció la formación de varios núcleos ideológicos, siendo el gaditano uno de los principales (6).

El final de la década de los setenta, periodo que marca el fin de la primera etapa krausista (7), se produce un importante cambio en la marcha de este núcleo, con la aparición de dos iniciativas de peso: la Real Academia Gaditana de Ciencias y Letras en 1876 y, dos años más tarde, el Boletin Gaditano, revista literaria quincenal y órgano de expresión de la también recien creada Academia Gaditana de Ciencias y Artes (8). Desde el principio de su funcionamiento, la Academia de Ciencias y Letras va a desarrollar la búsqueda de un sistema, cuyo fin sería facilitado por la ciencia y por la razón (9). Elementos ambos que posibilitarían al hombre su relación con Dios. Una vía por lo tanto, única y racional. Frente a este racionalismo krausista, y frente al positivismo imperante, la defensa de los católicos de sus postulados, pone nuevamente en candelero la antítesis razón-fe y ciencia-progreso. Es en este contexto donde debemos encajar las primeras polémicas, suscitadas entre el Académico krausista Romualdo Alvarez Espino, y el escritor y erudito gaditano Adolfo de Castro defensor de los intereses católicos, polémica suficientemente estudiada por Juan López Alvarez (10). En líneas generales, Castro venía a dar en la clave de las tesis sostenidas por los defensores del pensamiento católico y en donde, por encima de todo, se destacaba la inexistencia de una fe racional, la incompatibilidad de la fe con

(6) Al respecto, Teresa Rodríguez ahonda en los precedentes de la influencia cultural alemana, desde los inicios del XIX, con los ejemplos de Böhl de Faber, Alberto Lista o Henri Ahrens. RODRIGUEZ DE LECEA, Teresa. "Influencia de la cultura alemana en la primera mitad del siglo XIX". Sociedad, Politica y Cultura en la España de los siglos XXX y XX, Madrid, 1973 y JIMENEZ GARCIA, A. "El Krausismo y el pensamiento liberal español": Gades, Cádiz, 1983, n. 11.

(7) Insistimos que al anterior periodo en el cual, el krausismo intenta monopolizar la vida politica y educativa, teniendo como plataforma la Universidad Central de Madrid, le sigue otro en el que la Restauración acabará con este predicamento propio del Sexenio, y donde va a ser combatido tanto por la ortodoxia católica como por el positivismo oficial del sistema. Esta actitud intrasigente del nuevo orden, generará un actitud defensiva a través del institucionalismo. En este contexto se fraguará la Institución Libre de Ensañanza y las entidades de menor índole. V., LOPEZ; Juan. "Art.cit". y. TUÑON DE LARA, Manuel. Medio siglo de Cultura española (1885-1936), Madrid, 1977.

(8) Aunque en General, tanto la Academia de Ciencias y Letras, como la de Ciencias y Artes, o la posterior de Buenas Letras (1880), conformaron una plataforma de desarrollo y opinión de estas doctrinas racionalistas, no negamos el mayor peso específico de la primera en cuanto a bagajes y resultados de sus miembros, así como considerar al Boletin Gaditano, como un importante vehículo de expresión en torno a estas ideas. V., RAMOS, A. Cádiz en el siglo XIX..., pp. 131-158 y VV. AA. Prensa Gaditana (1763-1936), Cádiz, 1987.

(9) Junto al concepto de Ciencia, otras disciplinas humanas como el arte o la poesía también se adecuaban a facilitar este acercamiento entre el hombre y Dios. El campo artístico sería un plano de encuentro y relación entre el hombre y Dios, donde se desarrollaría una especie de paralelismo de acción, entre un Dios creador y un hombre artista. Para más datos al respecto, V. MARCHENA, José. "La Academia de Bellas Artes, en la encrucijada de la Restauración: 'una interpretación de sus discursos", Tercer Coloquio de Historias Locales, Cádiz, 1992.

(10) Dando como precendentes las famosas polémicas entre Federico de Castro y el Canónigo Mateos-Gago en Sevilla, o las de Tomás Romero y Fernández Valbuena en Badajoz, López dibuja las teorías racionalistas de Alvarez Espino en torno a Dios y a la religión, y las enfrenta con las refutaciones de Castro, en pos de las revelaciŏn divina. Al respecto dice el segundo: "La fe no es virtud terrena sino don de Dios: es la que dá luz al entedimiento, es la que dirije la voluntad, y es la que noticia los secretos que Dios revela a los pequeño..."; y 
las verdades naturales y el conocimiento humano de Dios a través de la fe, del dogma y de la revelación divina. Por contra, Alvarez Espino se ubicaba en el contexto decimonónico para definir como insostenible en pleno siglo XIX, cualquier sistema apoyado en el milagro y en lo sobrenatural, toda vez que el hombre debía hacer uso de la conciencia más que de la creencia y la fe. La alianza entre la religión y la ciencia era el único modo de curar los males públicos, y asegurar la moral individual y la justicia social. En clara alusión a la teoría panenteista (11), Alvarez Espino sostenía que la razón tocada por el dedo de Dios, engendraría una ciencia sana y facilitaría a su vez un estado de armonía -otro concepto krausista-, con la fe (12).

No obstante y como esto se había de suponer, la polémica entre la fe y la ciencia no había hecho más que empezar. Dos años más tarde, el discurso del cura castrense Pablo Medina Guerrero en la misma Academia y su contestación por el académico y jurista José $\mathrm{M}^{\mathrm{a}}$ Fernández de Cires, volvía a sacar el tema a la palestra. Medina, por parte de los defensores de la tradición católica, veía bueno el progreso técnico y científico del siglo, pero también era consciente de que se había ido de las manos o, dicho de otra forma, había conducido a la sociedad europea al materialismo y al positivismo olvidando los presupuestos espirituales: "Los adelantos materiales, por sí solos -sostenía-, no constituyen ni mucho menos, la verdadera civilización, esto es, el hombre no vive solamente la vida del cuerpo; necesita además la vida del espíritu, la vida del alma, sin la cual no podía conseguir nunca un progreso perdurable y verdadero" (13).

en cuanto a la ciencia como única y posible vía opina: "La ciencia del hombre es con relación a su vida mortal: esto nada puede enseñar para la vida del espíritu. Católicamente hablando, la ciencia del hombre en cuanto a Dios, solamente de Dios puede venir". CASTRO, Adolfo de. El Racionalismo en la Real Academia Gaditana de Ciencias y Letras, Cádiz, 1877, pp. 7-37. V. además, LOPEZ, J. "Art.cit"., REAL ACADEMIA GADITANA DE CIENCIAS Y LETRAS Sesión solemne celbrada por... con motivo de la recepción del Señor $D$. José Ma Fernández de Cires el 27 de mayo de 1877, Cádiz, 1877, RODRIGUEZ DE LECEA, T. "El Krausismo español como filosofía práctica". Sistema, Madrid, 1982 y GARCLA CUE, Juan Ramón. Aproximación al estudio del Krausismo andaluz. Madrid, 1985.

(11) No nos resistimos a aludir al panenteismo, como solución intermedia a los ataques hacia el krausismo, de ser una doctrina deista y panteista. Dios como realidad única y total por encima de la naturaleza y el espíritu, se encuentra en la esencia de todas las cosas, pero sin confundirse con éstas, por lo que naturaleza y espíritu gozán también de una parte independiente. Esta cuestión, fue también uno de los principales caballos de batalla de los teóricos krausistas españoles. V. entre otros, UREÑA, Enrique Mâ. "La actualidad del Krausismo". Revista de Occidente, Madrid, 1989, $\mathrm{n}^{\underline{Q}} 101$ o VALIÑO, Marcelino. "El panenteismo de Antonio Machado". Revista de Filosofía y Didáctica, Madrid, 1983, $\mathrm{n}^{\mathrm{Q}} 1$.

(12) En realidad es lícito anotar que Adolfo de Castro, bajo el pseudónimo de Jacinto Flores Estrada, lanza sus críticas contra los postulados de la Academia en otro folleto -recopilación de artículos de prensa-, publicado también en 1876. Junto a los escritos en su favor que lo ponen por las nubes, Castro también se encontrará con la censura del "otro lado", con calificativos tales como ser negativo o ser derrotista ante la obra de cualquier ilustrado y cientifico gaditano. V. El Academicastro, o sea D. Jacinto Flores Estrada (colección de...) Estes artículos ban visto la luz pública en la prensa gaditana, Cádiz, 1876, CASTRO, A. d. op. cit. y REAL ACADEMIA GADITANA..., Cádiz, 1877.

(13) REAL ACADEMIA GADITANA DE CIENCIAS Y LETRAS Sesion solemne celebrada por... con motivo de la recepción del Señor D. Pablo Medina y Guerrero el 22 de mayo de 1879, Cádiz, 1879 , pp .11 y 12 . 
Para Medina las corrientes filosóficas alemanas, habían conducido a la confusión y a la contradicción, cuyo idealismo era culpable del peligro de olvidar los aspectos espirituales (14). En esta dinámica habla del panteismo y rechaza la doble reflexión hegeliana: tanto la de ver a Dios en contínua evolución y transformación en la naturaleza y el hombre, como la del hombre tomando conciencia de sí mismo por la razón, que le convertía en parte misma de Dios. Reflexiones que para Medina, no conduceden sino a la omnipotencia racional, donde todo puede tener justificación:

"No el materialismo, porque este no es otra cosa que la negación de toda idea sublime, de toda acción noble, de todo sentimiento generoso; no el racionalismo, porque este, al degenerar en el panteismo desconsolador, confunde con la noción de Dios y la de la personalidad humana, las ideas de lo bueno y lo malo, de lo justo y lo injusto [...] destruye la legítima relación existente entre Dios, la humanidad y el hombre [...] si el hombre no es más que materia, a nada tiene derecho y si es Dios lo tiene a todo, y por exceso o por defecto la noción de derecho queda destruida" (15)

Finalmente, su crítica global a la filosofía moderna lo pone en situación para definir a la, "...filosofía católica como la única, justa y cierta" (16)

Frente a estos presupuestos, Fernández de Cires intenta demostrar que la filosofía moderna - de la que obviamente es defensor-sî había contribuido al progreso moral. Fernández recurría a la historia para justificar la evolución y el progreso del hombre, como evolución de un ser imperfecto y finito, a la que la filosofía moderna a duras penas podrá solventar pero que, ni mucho menos, podrá llegar a confundirse con la perfección e infinitud de Dios. Por eso mismo la distinción entre Dios y el mundo -en defensa de las acusaciones de panteista-, es obviamente clara (17)

No se nos olvida hacer referencia de la segunda gran iniciativa krausista al comienzo de la Restauración: la publicación del periódico literario Boletín Gaditano, que desde sus inicios en 1878, desempeñó una labor claramente propagandística de estos principios racionales. Amén de los principales miembros de la corriente krausista gaditana, merece citarse la colaboración de escritores y políticos, si nó afines en la ideológía, sí en una onda muy cercana por su talante progresista: son los casos de Juan de Vicente Portela, Pedro Canales, el propio direc-

(14) Medina pone en solfa a pensadores como Kant, Locke, Krause o Hegel. Frente a un cerebro para los "materialistas", "asiento de las facultades sensitivas, intelectuales y afectivas y en relación directa a su actitud e inteligencia", Medina dice ser, "... centro de la operaciones de nuestra alma". Ibidem, pp. 12-24.

(15) Ibidem, pp. 26-58.

(16) Ibidem.

(17) Fernández de Cires se muestra decidido defensor de las nuevas corrientes filosóficas, tanto desde los altos estadios -grandes filósofos-, como en las "muchedumbres". Sobre lo evidente del camino católico, y frente a las posibles irregularidades de los nuevos sistemas apostilla: "No porque se nos enseñe un camino, al parecer trillado y sin obstáculos, debemos seguir por él con los ojos cerrados, que acaso conduzca al abismo. Necesitamos examinarle con cuidado, pero sin prevención; y al notar el peligro dar la voz de alarma. Ibidem, pp. 50-52. 
tor del rotativo Faustino Díaz Sánchez o la escritora Patrocinio de Biedma, y eso sin contar los frecuentes artículos anónimos o bajo pseudónimos. En general, el balance ideológico viene a hacer referencia sobre las mismas constantes descritas desde el inicio de nuestro artículo: idea del progreso frente a lo retrógrado, sentido racional de la historia y la vida humana (18), y unión final y armónica con Dios a través de la ciencia. En 1884 un fragmento de artículo, en atractivo y sugerente tono, planteaba lo siguiente:

“...¿Os asusta quizá la idea de que profundizando en los estudios científicos os hallaréis sin pensarlo enfrente de la verdad revelada?...lejos de vosotros tal idea; la fe y la razón son dos ríos nacidos en el mismo valle corren paralelos, sin que sus aguas mútuamente se enturbien..." (19).

Entretanto otras opiniones autorizadas en Cádiz, defendian al progreso y a la ciencia desde un punto exclusivamente técnico y claramente separado de lo religioso (20), otros escritores en la órbita gaditana como el sevillano Narciso Campi-

(18) En concreto, Juan de V. Portela describe a la historia como una evolución, cuyos primeros episodios sin ciencia dan paso a la aparición de ésta, gracias a la providencia de Dios: “...el hombre sintió necesidad de estudiar, y en esta aspiración de su inteligencia, en esta condición de su espíritu tuvo origen la ciencia". De hecho, a su juicio, de no haber aparecido la ciencia el hombre hubiese quedado en un estadio de sociedad ignorante, gran enemigo en la doctrina krausista y por la que habría que combatir, so riesgo de un desenlace apocalíptico fatal. V., Boletin Gaditano, 15-oct.-1878.

(19) Boletín Gaditano, oct.-1884, n. 1. De nuevo Portela dá en las claves de esta reflexión; "cuando el hombre puso en ejercicio su pensamiento, comenzó la plenitud de su naturaleza; el hombre se hizo coadjutor del creador, el día en que puso a mano a la ciencia". En el fin último de esta ciencia se prevé la unión con Dios, que conlleva el afecto, la atracción y la libertad de pensamiento, a través de la ciencia. Otros aspectos derivados fueron tratados de igual forma, como el positiviśmo material frente a la ciencia y la razón por Pedro Canales, o la necesidad del progreso a través de la instrucción e ilustración a las clases populares, como medio para lograr el progreso de la comunidad humana. Ibidem y además, art. de Pedro Canales "Imprecación". Boletin Gaditano, 15-oct.-1880, art. de L. A., "Ilustración", per, cit., 15-sep-1880, "Discurso de Doña Patrocinio de Biedma ante el Congreso Literario", per. cit., suplemento, may.-1878 y art. de Faustino Díaz Sánchez, "Al progreso", per. cit., 1jun.-1880. V. también ESPIGADO, Gloria. op. cit., pp. 315-345.

(20) Sobre este parecer, podemos citar dos ejemplos. El primero, en el certamen literario desarrollado en el Ayuntamiento gaditano, con motivo de la boda del rey Alfonso XII. Al discurso de un capitán de Fragata llamado Osteret, pleno en mensajes de progreso marítimo y misión civilizadora de España, Vicente Rubio y Díaz hablaba del desarrollo y avance de la ciencia, sin referencia alguna a la fe o al asunto divino. Apreciaciones que, en cualquier caso, quedan contrastadas con la presencia al acto de Alvarez Espino quien, en calidad de presentador del fallo del jurado, aprovecha sus consignas de aliento a la instrucción para meter una cuña en pro del racionalismo en armonía con la fe: "...y tras la victoria que la religiosidad de la vida supone sobre el propio corazón, ninguna tan grande y hermosa como la que alcanza la sabiduría sobre las conciencias de los hombres".

Sobre el segundo Emilio Gamborg, dos años más tarde, exaltaba también la importancia de la ciencia y la razón, pero con independencia de lo espiritual: "expansión a las facultades de la razón, pero no a las expensas del corazón y de la fe, por más que el trato de problemas científicos debe ser científico, no religioso". V., Acta de la sesión solemne y pública 
llo, publicaban en la malagueña Revista de Andalucia, las grandezas del siglo XIX pero uniendo a éstas la mano divina:

"Con el siglo está Dios: Dios le defiende; le muestra Dios el ideal futuro/ a su hondo afán, a su conciencia abierto./ Si aún torpes nieblas el error extiende,/ faro habrá que disipe el velo oscuro,/ centelleante columna en el desierto./ De lo pasado muerto/ queda el pálido rastro; mas ya radiante el astro/ contemplan asomar de un nuevo mundo/ cuantos viven la vida de la ciencia,/ cuantos escuchan con desdén profundo/ el mísero clamor de la impotencia:/ y joh, mi siglo, el mayor que vió la historia!/ cuantos tus hijos con amor se llaman,/ y obreros y cantores de tu gloria,/ tu peso llevan y tu nombre aclaman" (21).

Ni que decir tiene, que la labor de los dos principales bastiones del grupo krausista gaditano, había ya fructificado en diversas publicaciones por estos años. Sus labores docentes y pedagógicas, se alternaban con las académicas, dando buena fe de una considerable capacidad de trabajo.

Alvarez Espino volvía a insistir en la exaltación al progreso y a la ciencia como equivalentes a Dios (22), contraponiendo a este planteamiento racional los valores mundanos y materiales. Efectivamente, Alvarez Espino insistía en la idea del universo armónico y panenteista, cuya razón de ser venía dada por Dios: "Para que la materia no fuera la muerte -sostenía-, Dios la dió por alma la fuerza [...] desde entonces un factor obra sobre el otro, y la creación se hace: el uno no

celebrada el 24 de octubre por el Ayuntamiento, para la adjudicación de los premios alcanzados en el certámen literario y artístico, promovidos con motivo del enlace de S. M. D. Alfonso XII con S. A. Doña Mercedes, Cádiz, 1878, pp. 9-33 y GAMBORG, Emilio. Excursiones sobre terrenos económìcos, Cádiz, 1880.

(21) Composición de Narciso Campillo, "al siglo XIX", Revista de Andalucía, Málaga, 1878, T.XIV e IRIARTE, J. "La aventura krausista y su evolución en fuerza histórica nacional". Razón y $F e$, Madrid, 1962, n. 62. En general, la citada revista publicó por estos años, numerosos artículos, de escritores gaditanos que, amén de estos temas, los desarrollaron también, sobre proteccionismo y antitauromaquia.

(22) En esta composición titulada "El oro y la ciencia", publicada en el Boletín Gaditano, 15-ag. 1878, Alvarez Espino insiste en la exaltación de la razón y el conocimiento por encima de las realidades materiales que como el dinero, sucumben ante lo incuestionable de los primeros:

"Y mientras tanto, con que sólo vibre/ sus alas la razón, alzando al vuelo,/ bebe la ciencia en el raudal del cielo/ y hace con su verdad al hombre libre!/ [...] Mientras si busca, con afán que asombre,/ la sublime conquista de la ciencia,/ a la par que ilumina su conciencia./ logra virtud, y libertad, y nombre./ [...] Sólo la ciencia los misterios sabe/ que al hombre dan vigor, ventura y calma:/ ello sólo mostrarle puede el alma/ de la existencia racional la clave/ [...] Y justicia a los dos hace la gente;/ que el rico panteón fiero derrumba,/ y al ver del sabio la modesta tumba/ con respeto y amor dobla su frente".

Incluso en el ámbito de la propia Academia o en eventos del momento como la Exposición Regional de 1879 , insistía en las claves para una auténtica regeneración gaditana que, necesariamente pasaban por las consignas de la razón: progreso intelectual, luces del pensamiento, religiosidad de la vida y sana ciencia. V., Real Academia Gaditana de Ciencias y Letras: inauguración del curso académico de 1877 a 1878, Cádiz, 1877,; p. 220, Real Academia Gaditana... curso académico de 1881 a 1882, Cádiz, 1881, p.18 y Boletin Gaditano, 1-ag.-1879. 
puede estar sin el otro porque no puede estar parado". Sin apartarse del esquema en el que naturaleza y espíritu viven en común resalta cómo el hombre, dotado de inteligencia y conocimiento, se destaca del resto de los elementos vivos:

“...el espíritu humano es más potente, más noble, más admirable en todas sus manifestaciones: sus facultades son más ricas y sus funciones más variadas que la de los agentes físicos que actuan en el mineral, que los de la vitalidad vegetal, y que las sensibles y locomotores de la escala zoológica. El alma no rechaza la proximidad del mundo químico, ni la influencia del fisiológico [...] nos agrega a ello una luz que es fuente de nueva vida, un calor que es gérmen de nuevos movimientos, una fuerza [...] que es razón de mayores y más preciosas transformaciones. Esta ley se llama inteligencia, este calor sentimiento, y esta fuerza [...] conciencia" (23).

Pero frente a este esquema armónico y dinámico, el hombre está expuesto a caer en una serie de vicios sociales y valores trasnochados de índole material -el lujo, el dinero, la ostentación, el valor-, aspectos que sólo pueden ser superados a través del conocimiento científico y de la razón (24). Dentro de este paquete de vicios sociales se encontraría la hipocresía y como variante de ésta, la hipocresía religiosa. Esto es, aquellas religiones excesivamente simbológicas y faltas de realidad, como el caso de la religión católica, apostólica y romana, "...embozo de miserias y pantalla para planes criminales y pecaminosos". Para Alvarez Espino, dos elementos negativos confluyen en el planteamiento dado hasta ahora por la religión cristiana (25): en primer lugar, el peligro de convertir a la religión en un culto idólatra, donde lo material y la ostentación social, va postergando a los verdaderos valores de orden interno:

"Así es que un rosario, una vela, un puesto en las procesiones, un estandarte de algunas arrobas, unas horas pasadas en el templo y unos golpes dados sonoramente sobre la pasta del libro de misa o sobre la cartera en que se esconden en el pecho las claves de nuestra virtud y de nuestra posición social juntamente, son de un admirable efecto para la sociedad, que guarda toda la malicia para el bueno y derrama todas sus bondades sobre el perverso" (26).

(23) ALVAREZ ESPINO, R. Errores de educación: páginas de crítica social, Cádiz, 1878, pp. 5-17.

(24) Ibidem, pp. 23-31, y 147-220 y ALVAREZ ESPINO, R. "La Mujer", Disertaciones y Discursos, Cádiz, 1883, p.248. También merece una especial atención los versos de la composición "Una Magdalena", donde Alvarez Espino teoriza sobre la camalidad y lo material -placer, joyas, dinero- de Magdalena como prostituta arrepentida, para enfrentar conceptos como materia-alma, carne-espíritu, etcétera. ALVAREZ ESPINO. R. Una Magdalena, Cádiz, 1881, pp. 11-29.

(25) Este parecer en torno a la Iglesia, coincidía con los presupuestos de Gumersindo de Azcárate que la consideraba como freno al progreso social, y con predominio de la jerarquía, lo espiritual y lo sobrenatural, en vez de ser base a una creencia natural, racional y universal. MARCOS OTERUELO, A. El pensamiento de Gumersindo de Azcárate, León, 1985, p.334.

(26) Ibidem, pp. 100-101. 
En segundo lugar, el riesgo de consolidar una creencia basada en lo dogmas, en el miedo de no aceptarlos y en el carácter amenazador: "...se ha creído que se sería más religioso, pensando más en el diablo". Critica el temor que se le inculca a los niños en su educación, reflejando los aspectos religiosos y sus realidades, como medios de amenazas, al igual que el sacerdote con sus feligreses. Por ello, y ante una religión que, como la cristiana, debe ser ante todo, "...luz para la mente, confianza para el corazón, y esperanzas de amor y gloria para el alma", se vuelve al recurso de la ciencia y la razón, como única verdad y forma para conocer a Dios y a sus manifestaciones religiosas:

“...dejad que la ciencia espante los fantasmas del error y las alimañas de las viejas preocupaciones y las pavorosas creencias, y que el fuego del sentimiento derrita el falso metal de nuestras supersticiones, y lance de sí, como lava inflamada por la impostura, la escoria de esas grotescas y pueriles ficciones [...] esas nubes y esas tempestades son dudas y conmociones que sólo sirven para comprobar y hacer más apetecibles y más firmes la tranquila irradiación de la verdad y la viva llama del amor, los precisos seguidores de las ciencias y las bellas esperanzas de la fe." (27).

También Alfonso Moreno Espinosa partía de la idea del progreso, como base de sus teorizaciones filosóficas. Para éste, las conquistas de la ciencia y las sofisticaciones técnicas, generadoras de tantos inventos como la aplicación del vapor, lá locomotoras, la apertura de canales, el telégrafo, la fotografía, el pararrayos, el cloroformo y tantos otros avances de la medicina y demás disciplinas científicas, habían supuesto un periodo -el siglo XIX-, de grandes cambios y contrastes no detenido todavía: "¿aún no te basta haber hecho del sol un dócil siervo, un humilde pintor?...", decía este pensador abulense, quien apostillaba este planteamiento en pos de la ciencia y el progreso, como vía de acercamiento y proximidad a Dios (28).

Las citas bíblicas le servían para aproximar y dar empaque al carácter del progreso, como fruto del trabajo justo y digno del hombre: "Con el sudor de tu frente/ gana en adelante el pan/ y el hombre con rudo afán/ cumple el decreto

(27) Ibidem, p.119. Años después, Alvarez Espino asentía estos pareceres con este texto redondo y sin desperdicio, en donde combinaba, en perfecta armonía, la fe con la razón:

"El Dios de los cielos no puede exigir mejor culto al sabio, ni el Cristo de la tierra puede verse mejor interpretado en este punto por la humana ciencia. Cada pensamiento es un tributo de sumisión a la omnipotencia y cada sentimiento es un holocausto de amor al supremo Dios; cada propósito, es una demostración de rendimiento ante la providencia; cada acto es un obediencia al legislador de nuestros destinos; cada conciencia es un templo; cada corazón un altar; cada virtud una oración...". ALVAREZ ESPINO, R "Sociedad Protectora de Animales y Plantas". Disertaciones y Discursos, Cádiz, 1883, p. 105.

(28) Art. de Moreno Espinosa titulado, "A la Ciencia", en Boletin Gaditano, 1-ab.-1880. Incluso a la hora de exaltar algunas novedades de la ciencia, aprovechaba las posibles conexiones para reforzar esta idea de proximidad divina. Tal fue el caso de la fotografía de quien decía: "...así el hombre marcha en pos/ de la ley de eternidad,/ y adquiere la ubicuidad,/ asemejándose a Dios/ [...] ;Oh Dios! te traigo la copia/ del que fue tu imagen propia/ y que se llamaba el hombre". MORENO ESPINOSA, A. Coplas Callejeras, Cádiz, 1884, p. 240. 
divino,/ y del progreso el camino/ abre al humano linaje" (29). A su vez, la ciencia y el progreso es para Moreno Espinosa, liberadora de trabas tradicionales en desuso: "Cada invento científico es la muerte de alguna institución, ley o creencia". Por ejemplo el telégrafo, supondría un medio para unir y hermanar a los pueblos, así como de romper las fronteras y obstáculos diversos; algo así pasaría con el ferrocarril, los canales, etc. (30).

Al igual que Alvarez Espino, critica la desviación de la iglesia ante la doctrina católica, excesivamente basada en los incuestionable de sus dogmas (31). Sin renunciar en ningún momento de la creencia en Dios, Moreno Espinosa insta la vía razón-fe como única posible para alcanzar la verdadera unión religiosa:

"...hoy, que hace testamento el alma mía,/ quiero dar testimonio/ de que, por más que de ello se tilde/ mi siglo no es ateo./ Yo, el cantor más humilde/ pero el más entusiasta de tus glorias,/ en tí, Dios de bondad, ferviente creo;/ Te siento en mi conciencia,/ y penetrando de tu santa esencia/ y nadando en tu luz el mundo veo" (32).

Nuevamente, el dualismo razón-fe, Dios-hombre, es la culminación de ese gran cúmulo de adelantos científicos que no hacen sino acercar al hombre para convivir y conocerse más. En suma acercarse y conocer más a Dios (33).

Finalmete otro aspecto, quizás el más original al respecto, desarrollado por Moreno espinosa fue el referente a su oposición a la guerra y a sus críticas al mito imperialista español, idea que conllevaba la adopción de una actitud más acorde con los tiempos actuales de progreso y desarrollo científico. En realidad esta idea entronca con la pretendida unión solidaria de la humanidad a través de los inventos y las mejoras técnicas. Moreno Espinosa considera que el capítulo de la guerra en la historia del hombre, había dejado de tener sentido (34), por

(29) Composición de Moreno Espinosa, "El Trabajo", publicado en La República, 11-dic.-1897.

(30) MORENO ESPINOSA, A. Coplas Callejeras, pp. 44-47, 73-74, 216 y 269. Quizás en una mayor vertiente social que Alvarez Espino, Moreno Espinosa resalta algunos aspectos como la asociación, las mejoras de las condiciones laborales del obrero o incluso la juventud, como realidades asociada directamente a las ventajas del progreso científico. Ibidem, pp. 42-47 y 216-219.

(31) Esquema que para Moreno Espinosa, podría suponer hasta la renuncia ante un Dios dogmático y despiadado, y en donde aparecen hasta pinceladas del pasado inquisidor:

"...Si no hay más Dios que el ser abominable/ antropófago, horrendo, que de ira/ cual león hambriento con espanto ruge, / y de la ardiente pira/ donde la carne del hereje cruje,/ aspira el humo y se calienta al fuego/ con bárbara delicia,/ entonces jay!...si, si de Dios reniego...". V., Ibidem, pp. 319-320.

(32) MORENO ESPINOSA, A. Ibidem, pp. 319-320.

(33) Ibidem.

(34) Para Moreno Espinosa, conceptos como gloria militar, heroismo, etcétera, no hacen sino ocultar la triste cara de la destrucción bélica y de sus tristes episódios históricos, que ven cercano su final;

"Si ayer la guerrera trompa/ sonaron hijos de Apolo,/ hoy al trabajo tan sólo/ cantarán con mayor pompa./ Ya es preciso que se rompa/ todo belicoso lema,/ y cambiando de sistema,/ salga de la edad presente/ en verso digno y valiente/ del trabajo el gran poema". "El Trabajo", en La Repüblica, 11-dic.-1897. V. también, "A la Ciencia" en Boletín Gaditano, 1 ab.-1880 y Coplas Callejeras, pp. 48-52 y 113-115. 
otro con predominio de la armonía, la paz y el trabajo: “iAdelante! obreros de la idea, espíritus de ley, en vuestros hombros lleváis el arca santa del progreso; ¡caiga por siempre reducida a escombros el alcázar del mal! iguerrra a la guerra; y que el reino de Dios baje a la tierra!" (35), teorizaba como gran objetivo universal, o esta otra que contraponía periodos de la historia con sus respectivos "útiles":

"Llegarán felices horas/ en que todas las naciones/ derretirán. sus cañones/ para hacer locomotoras;/ cuyas ruedas voladoras/ por carril tendrán debajo/ las armas que templa el tajo; que, para bien de la tierra,/muere la edad de la guerra/ y viene la del trabajo" (36).

Dentro de la nómina de krausistas gaditanos de empaque, y amén de los dos principales citados, destacamos con luz propia el hacer del escritor y poeta José Larrahondo. A pesar de la coincidencia en aspectos básicos, los planteamientos de Larrahondo para con la religión tienen un punto de partida más humano y material que racional. Desde la misma relación entre Dios y el hombre, a su juicio, surge un error comparativo, aunque sin renegar de la libertad como ser vivo creado por aquel: “...si somos grandes por Dios -manifiesta-, no podemos ser pequeños ante ese mismo Dios [...] estudiemos al hombre tal cual es, libre por esencia, de hecho, por sus facultades intelectuales subordinado en derecho por sus atributos materiales" (37).

Al igual que Alvarez Espino y Moreno Espinosa, critica los elementos contraproducentes a la religión cristiana -"...dogma, cadalsos, templos, héroes, verdugós y vitrinas..."- y la exalta como bastión en sus conquistas en la era moderna atunque asignándole -y esta es su novedad- un carácter social y humano: "Despejad a Jesucristo de sus atributos celestes: presentadle creyente o revolucionario, y la religión quedará reducida a la enunciación de una simple reforma social" (38).

Finalmente su consigna en torno al hombre y su unión hacia Dios, se ejecuta en forma de Dios humano, de la exaltación de sus virtudes y de su lugar en el universo creado por Dios:

"La Trinidad moderna, el nuncio de la redención, no brotó en el Calvario, brotó en el hombre. Libertad, igualdad, fraternidad. ¿Hace falta un Dios? Pues también puedo daros un Dios, licuado primero en las retortas de la

(35) Composición de Moreno Espinosa "A la Ciencia", en Boletín Gaditano, 1-ab.-1880.

(36) MORENO ESPINOSA, A. Coplas Callejeras, p.47. Incluso usa de nuevo el contexto evangéli$\mathrm{CO}$, para describir al poder del Dios como liberador de la guerra y pacificador del hombre:

"Ojalá que, sentados a tal mesa/ en banquete de amor y: eterna paz,/ cuantos pueblos y razas tu luz besa/ felices miran siempre joh sol! tu faz./ Tenga la nube de vapores irojos/ con que empaña la guerra tu alba ley, y en triunfo moren por doquier tus ojos/ la ley del mártir que expiró en la cruz". Ibidem, p.158.

(37) LARRAHONDO, J. Errores politicos, Cádiz, 1887, pp. 3-7.

(38) Esta vertiente social de la religión, es lo que hace a Larrahondo caer en un escepticismo ante aspectos tan básicos de la creencia como la teoría de la creación, e incluso ridiculizar el juicio final y el apocalipsis. Ibidem, pp. 16-25. 
infancia, purificado luego en el fuego del sacrificio y acrisolado más tarde en los espejismos de la naturaleza. Mi Dios es la justicia. Ese es el Dios de los hombres" (39).

Entretanto la situación en Cádiz, sigue con una división entre los defensores de la concepción tradicional cristiana, y los defensores de estas nuevas doctrinas racionales. Del primero y frente al aluvión de entidades favorecedoras de las nuevas corrientes, algunos "bastiones" en pos de la tradición, llegan a contar con el apoyo directo de influencias tan contudentes como las del Rey Alfonso XII o del propio Leon XIII, como le sucedió a la Hermandad de Caballeros Hospitalarios. $\mathrm{Ni}$ que decir tiene que su repulsa a las nuevas "concepciones eran a menudo manifiestas, como esta condena del capellán e intelectual Servando Arbolí:

"Cuando nos avasalla el espíritu libre pensador y que de todo discute, entiendo que no es la discusión la destinada a salvarnos [...] sino la predicación severa del Evangelio en sus máximas de salud y con su fuerza creadora [...] aplaudo las intenciones pero no admito la eficacia de otro género de elocuencia desde las alturas del púlpito. Estamos tan hambrientos de verdades, como sobrados de letras, de filosofía, de erudición rebuscada y de oratoria de aparato, que nada engendra para el cielo [...] la fe es lo que vence al mundo" (40)

Mientras en el ámbito académico, se sucedían las reuniones y certámenes que a la postre, no hacian sino incidir en las doctrinas idealistas y en los conceptos de ciencia y de progreso unidos a la fe religiosa. Por ejemplo, en el certamen literario de la Academia de Ciencias y Artes de 1883, que fue ganado por Antonio Milego con un trabajo en favor de las Sociedades económicas, uno de los parrafos decía lo siguiente: "Si no admitiéramos lo perfectible y lo inmortal, no comprenderíamos jamás el estudio, la instrucción, el progreso. Por eso el edificio de la moderna civilización tiene tres gradas: religión, ciencia, libertad. Religión, por-

(39) Ibidem, p.25. Nuevamente Larrahondo usa este esquema krausista del universo, para justificar un fin en pos del progreso, sinónimo de civilización moderna, y en pos de la democracia, el modelo social óptimo de la humanidad. Una idea que ya había sido atisbada por Moreno Espinosa

"Si libertad, siempre libertad! Libre cruza el ave los celestes inconmensurables espacios: libre marchan las estrellas, unidad de la creación dentro de la uniformidad de lo increado: libre es todo, mundo y átomos: libre el alma, si existe alma, y libre el pensamiento del hombre. ¿Pretendemos coartar esa libertad? Imposible. Esa libertad forma la democracia que la democracia no es otra cosa que el derecho a la libertad".

Un estado de plena libertad que llegará a superar ampliamente la necesidad de dogmas y demás variantes de creencias: "El pueblo -sostiene-, necesita siempre un dogma, una religión, una creencia. Cuando le falten estas cosas creerá en la creencia de sí propio, en la religión del amor--ila religión del amor el dogma de la democracia!-" Ibidem, pp. 7 y 8 y LARRAHONDO, J. Discurso leído anta la Academia Gaditana de Ciencias y Artes, Cádiz, 1885, pp. 19-21. V. además, MORENO ESPINOSA, A. Musa Popular, Cádiz, 1878, p. IX.

(40) ARBOLI, Servando. Páginas Gaditanas, Cádiz, 1882, p.9. V. también, Consejo Provincial de Caballeros Hospitalarios, Cádiz, 1881, p. 11. 
que sin ella no se concibe la paz y la fraternidad universal. Ciencia, porque la ilustración borra las fronteras, salva las distancias y señala el adelanto y la prosperidad de los pueblos. Y libertad, porque el espíritu es la libertad misma, como la materia es el despotismo, y si negamos aquella, negamos lo que la naturaleza humana tiene de más sublime" (41)

Prácticamente y hasta el final del periodo de nuestro estudio, se mantiene esta tendencia. Las publicaciones y reflexiones en torno a los conceptos de Ciencia, Progreso y Fe de los Moreno Espinosa, Alvarez Espino o Larrahondo, se dejan influir en numerosos cauces ideológicos de la burguesía gaditana, dando paso a otros tantos exponentes. Valga como ejemplos de esta última fase los escritos de diversos poetas gaditanos publicados en 1892, donde se volvía a insistir en el siglo XIX, en el trabajo como ley divina, en la exaltación del progreso del hombre, en relación directa con Dios y el cristianismo, y en los planteamientos panenteistas (42); algunos escritores y estudiosos como Francisco Topete - “...único guía hábil e inteligente, que es la razón; momento de la esencia de Dios" (43)-, o José Méndez y Franzón en torno a un Dios absoluto y organizador del universo, entendido por el hombre a través de la razón:

"Dios es el principio armónico y creador por sí mismo; es el principio en el todo y el todo en el principio, es emanación divina y justísima de la libertad absoluta en el universo mundo, sin más límite ni cortapisa que su propia voluntad. Dios ha sido, es y será siempre, interpretado por el hombre, con arreglo a las vicisitudes de la vida de éste, y en relación directa a su desarrollo moral o intelectual" (44).

De igual manera en el discurso ideológico de algunos políticos que, sin culminar este esquema de relación fe-razón, sí echan mano de la importancia de la razón y los avances de la ciencia como Rafael Viesca (45), o en algunas posturas eclécticas aunque con evidente peyoración de la cuestión racional: "...los hombres en el racionalismo pugnan contran la fe y la creen [...] que todo lo pueden

(41) MILEGO, Antonio. Objeto preferente de las Sociedades Económicas, Cádiz, 1883. Otras obras, en concreto en la modalidad de verso, también incidían ẹ este concepto del progreso y la ciencia con Dios, como la composición del granadino Antonio Rubio o la "Oda a la libertad" de José Verde Montenegro. Cfr., Academia Gaditana de Ciencias y Artes. Certámen cientifico-artístico-literario.Trabajos premiados, Cádiz, 1883, pp. 39-43.

(42) Destacamos principalmente las composiciones de Servando de Dios, Rosa Martínez de la Costa, en pos de la ciencia unida a Dios -“...yo busco a Dios en la encendida nube/ que forma a su capricho la tormenta/ y hasta en la lana que el volcán arroja/ y hasta en la brisa que a las flores besa..."-, la sorna de Manuel Grosso de comparar el amor con la electricidad -"Hecho ya este brevísimo relato/ del amor y la ciencia en armonía,/ apreciable lector, voy a rogarte/ que a fuer de hombre sensato,/ no olvides mi teoría/ si llegas una vez a electrizarte..."- o la particular visión futurista de Joaquín Puyana de unir Marte con la tierra por un cable puesto en el Himalaya. Cfr., Poetas Gaditanos. Album poético, Cádiz, 1892, pp. 15-17, 39-43 y 46-47.

(43) TOPETE, Francisco. La Verdad o generalidades de la verdadera ciencia o generalidades de la única verdadera religión, Cádiz, 1908, pp. 12 y 13.

(44) MENDEZ Y FRANZON, J. Pensamientos y sentencias, Cádiz, 1898, p. 6.

(45) V. VIESCA, R. Discurso de...en el Centro Obrero de San Fernando, Cádiz, 1892, pp. 7-9. 
con el auxilio de la razón [...] la razón nada pierde en su mérito y valor porque la fe sale en su auxilio muchas veces" (46).

Por supuesto que tampoco faltarán las réplicas de los sectores católicos y tradicionales, como la del rotativo El Pueblo Católico en 1900, a raiz de las críticas de Diario Popular a aspectos del catolicismo y al lamento por el cierre de este último, de algunos periódicos gaditanos de peso como La Dinastía o Diario de Cádiz: "[la actitud de estos periódicos] es lanzar blasfemias horribles contra nuestra religión, llegando hasta atacar nuestro adorable dogma de la Inmaculada Concepción de María Santisima [...] es gestionar afanosamente que se levante una estatua al pontífice de la moderna impiedad, al cínico Voltaire, maestro en el arte de la calumnia que blasfemaba del Salvador del Mundo, llamándole el infame a quien había que aplastar..." (47).

En general, la incidencia sobre el concepto de fe, ciencia y progreso en el contexto ideológico gaditano, incide necesariamente -como ya apuntamos-, en un discurso más amplio que vierte sobre la dinámica del positivismo, del racionalismo y del cientificismo de la Europa y la España de entresiglos. Pero a su vez, nos es posible asignar unas connotaciones determinadas que bien pueden establecer un modelo, integrado en esta dinámica general, pero con peculiaridades propias. En este sentido, el tránsito de los elementos burgueses del sexenio al periodo de la Restauración gaditana se enmarca en la dinámica general, por el que la corriente krausista hubo de adaptarse a un segundo periodo, en el que brilló más la vía pedagógica -valga citar la aparición de la Institución Libre de Enseñanza como estandarte de esta tendencia-. En el caso gaditano, este grupo de krausistas -cuyo núcleo merece urgentemente un estudio exhaustivo (48)- que, desde los sesenta se habían acomodado en los cauces pedagógicos de las Escuelas de Primera y Segunda Enseñanza (49), continuaron su labor después del golpe de Sagunto, llegando a utilizar las aulas y las academias para desarrollar esta teorización en torno a la ideas y a la razón. Teorización que va a seguir encontrándose con la oposición de la concepción católica y tradicional, aunque ésta con menos exponentes, quizás por defender unas ideas bien asentadas en la urdimbre eclesiástica y por lo tanto, menos necesitadas de promoción, en un sistema en el que la Iglesia se adaptó convenientemente a los requisitos y beneplácitos del nuevo régimen canovista. En cualquier caso, el aporte racionalista al panorama ideológico del Cádiz de la Restauración verterá no sólo en un proyecto de actitud vital más actualizada y acorde con la explosión ideológica y científica del momento, sino como aporte teórico a una opción progresista, contextuada en general en un núcleo de burguesía ajena al turno liberal y conservador del "sistema Cánovas", y en segundo plano del protagonismo político, pero a la espera de momentos de mayores opciones, como sucedió con el período del Sexenio Democrático.

(46) Art. de un tal "Cristino", publicado en La Correspondencia de Cádiz, 27-en.-1902.

(47) El Pueblo Católico, 21-ab.-1900.

(48) De reciente lectura en la Universidad de Cádiz, ha sido la Tesis Doctoral de Manuela Rodtíguez Borrero sobre Romualdo Alvarez Espino.

(49) Incluso nos podrían resultar váliclos buscar precedentes en aquel núcleo fourierista de Abreu en Cádiz, donde ya se desarrollaba el modelo de universo armónico de Fourier, o en los propios núcleos demócratas y republicanos de Cádiz, donde localizamos, no sólo a Moreno Espinosa y Alvarez Espino, sino además a Canales, Campillo, etc. Cfr., MARCHENA, José. Op. cit. 